\title{
Take a TRP to beat the heat
}

\author{
Michael J. Caterina and Craig Montell ${ }^{1}$ \\ Department of Biological Chemistry, The Johns Hopkins University School of Medicine, Baltimore, Maryland 21205, USA
}

Temperature is a ubiquitous physical variable with a profound impact on living organisms. Obviously, because of its detrimental effects on cellular biochemistry and integrity, extreme temperature must be detected and avoided. Even subtle differences in environmental temperature, however, can provide valuable information regarding the presence of food, companions, predators, or just a cozy place to rest. As a consequence, organisms from bacteria to mammals have evolved mechanisms to survey their thermal landscapes. Thermotaxis, migration towards a particular range of temperatures, has been studied in numerous vertebrate and invertebrate species, and a few molecular components of their thermotactic machinery have been identified. For example, in Escherichia coli, where thermotaxis is regulated by a twocomponent system that directs the activity of a flagellar motor, cell-surface amino acid receptors of the methylaccepting chemotaxis protein family have been shown to exhibit opposite patterns of intracellular signaling, depending on whether the ambient temperature is closer to $16^{\circ} \mathrm{C}$ or $27^{\circ} \mathrm{C}$ (Nishiyama et al. 1997). In Caenorhabditis elegans, genetic screens have led to the identification of two cyclic nucleotide gated channels, TAX-2 and TAX-4, whose elimination results in impaired thermotaxis (Coburn and Bargmann 1996; Komatsu et al. 1996) and a third related channel, cng-3, required for normal tolerance to elevated temperatures (Cho et al. 2004). However, the actual temperature-transducing molecules in worms have yet to be defined. Indeed, much remains to be learned regarding the mechanistic details of thermotaxis and the degree to which this process is evolutionarily conserved.

In this issue, Rosenzweig et al. (2005) present compelling evidence that dTRPA1, an ion channel of the Transient Receptor Potential (TRP) family (Montell et al. 2002), is critical for thermotaxis behavior in Drosophila larvae. The rationale underlying this study is that one invertebrate TRP channel (dTRPA1) (Viswanath et al. 2003) and six vertebrate TRP channels (TRPV1, TRPV2, TRPV3, TRPV4, TRPM8, and TRPA1) have been demonstrated electrophysiologically to undergo channel opening in response to heat or cold, over a range of temperatures that is distinct for each channel (Caterina et al.

${ }^{1}$ Corresponding author.

E-MAIL cmontell@jhmi.edu; FAX (410) 614-9573.

Article and publication are at http://www.genesdev.org/cgi/doi/10.1101/ gad.1294905.
1997, 1999; Güler et al. 2002; McKemy et al. 2002; Peier et al. 2002a,b; Smith et al. 2002; Watanabe et al. 2002; Xu et al. 2002; Story et al. 2003). For instance, TRPV1, TRPM8, or dTRPA1 can be activated by temperatures $\geq 43^{\circ} \mathrm{C}, \leq 23^{\circ} \mathrm{C}-28^{\circ} \mathrm{C}$, or $\geq 27^{\circ} \mathrm{C}$, respectively (Caterina et al. 1997; McKemy et al. 2002; Peier et al. 2002a; Viswanath et al. 2003). In addition, gene disruption experiments have shown that TRPV1 is essential for normal heat-evoked pain sensation and thermal hyperalgesia in mice (Caterina et al. 2000; Davis et al. 2000), while a Drosophila mutant lacking another TRP channel, Painless, shows impairment in avoidance responses to noxious heat or mechanical stimuli (Tracey et al. 2003). Guided by these findings, and by the prior demonstration that Drosophila larvae and adults exhibit thermotaxis (Sayeed and Benzer 1996; Zars 2001; Liu et al. 2003), Rosenzweig et al. (2005) use in vivo short interfering RNA (siRNA) to disrupt expression of candidate thermosensory TRP channels, either individually or in combination, in Drosophila embryos. In particular, they focused on the genes encoding the Drosophila TRPV, TRPM, and TRPAs, as members of these TRP subfamilies are known "thermoTRPs." Simultaneous knockdown of a transgene encoding a neuronally expressed GFP provided an efficient positive control for this procedure. Then, using a simple behavioral assay, the authors evaluated thermotaxis in the resulting larvae.

Rosenzweig et al. (2005) first demonstrate that when late first- and early second-instar larvae that have been raised at an optimum growth temperature of $24^{\circ} \mathrm{C}$ are released into the $31^{\circ} \mathrm{C}-35^{\circ} \mathrm{C}$ zone of a $27^{\circ} \mathrm{C}-41^{\circ} \mathrm{C}$ thermal gradient, they migrate within 25 min towards cooler temperatures, closer to their growth temperature (Fig. 1). However, when expression of Drosophila TRPA subtypes or that of dTRPAl alone is disrupted at the embryonic stage using siRNA, they found that the resulting larvae no longer prefer the cooler temperatures, and distribute themselves evenly at temperatures above and below the release zone (Fig. 1). Critical to the interpretation of this behavioral phenotype is the elegant array of control experiments the authors include. For example, they demonstrate that dTRPA1 "knockdown" larvae exhibit normal motility in the thermal gradient, despite achieving a different distribution. They also observed no change in avoidance of an olfactory repellent (N-octyl acetate) or avoidance responses following contact with a $55^{\circ} \mathrm{C}$ probe, suggesting that the thermotaxis phenotype reflects a remarkably specific defect in responsiveness to 


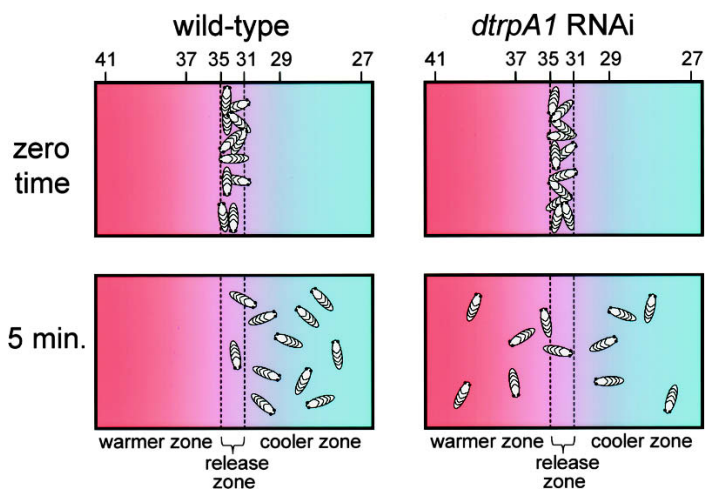

Figure 1. Larval thermotaxis assay. An agarose-containing Petri dish is set up with a thermal gradient extending from $27^{\circ} \mathrm{C}$ to $41^{\circ} \mathrm{C}$. Control larvae or larvae containing $d \operatorname{trp} A 1$ siRNAs (first or early second instar) are placed in the release zone $\left(31^{\circ} \mathrm{C}-\right.$ $35^{\circ} \mathrm{C}$ ). After $5 \mathrm{~min}$, the number of larvae in the cooler or warmer zones is counted, and a mobility index is calculated.

modest temperature changes. Conversely, the authors demonstrate that siRNA knockdown of the two Drosophila TRPV channels or one Drosophila TRPM channel has no detectable impact on thermotaxis, nor does genetic disruption of the Painless gene, further indicating that avoidance of extreme heat and avoidance of less extreme warmth are mediated by different molecular mechanisms.

Using a dTRPA1-specific antiserum, Rosenzweig et al. (2005) go on to find that this protein is expressed in a only a few locations, including two groups of central brain neurons, the corpus cardiacum, two pairs of cells adjacent to the developing mouthhook, and in the developing gut. Interestingly, no dTRPA1 expression is observed in the multidendritic cells. These body wall neurons express Painless (Tracey et al. 2003), are essential for withdrawal from a $55^{\circ} \mathrm{C}$ probe (Tracey et al. 2003), and have been reported to exhibit an increase in intracellular $\mathrm{Ca}^{2+}$ upon warming to $40^{\circ} \mathrm{C}$ (Liu et al. 2003). However, selective inhibition of multidendritic cell signaling with a genetically encoded tetanus toxin light chain (TeTxLC) has no impact on thermotaxis-nor does TeTxLC expression in chordotonal organs, which have been reported to show increases in $\mathrm{Ca}^{2+}$ in response to either modest warming or cooling (Liu et al. 2003). In contrast, as anticipated from the dTRPAl siRNA knockdown phenotype, transgenic expression of TeTxLC or the cell death-related protein Hid under the control of the dTRPA1 promoter (which appears to drive expression selectively within the two populations of dTRPA1positive central brain neurons) reduces thermotaxis efficiency, albeit to a lesser extent than dTRPA1 knockdown. These anatomical and transgenic experiments further highlight the distinction between mechanisms responsible for thermotaxis (at least in the temperature range tested by Rosenzweig et al. [2005]) and noxious thermosensation. Rosenzweig et al. (2005) also identify dTRPA1 as the first molecular marker for a subset of neurons required for Drosophila thermotaxis and support the notion that this warmth-gated ion channel, in fact, functions as a critical thermotransduction molecule in this process.

The segregation of different thermosensory functions among different cell types appears to be a conserved evolutionary theme. In mammals, different subpopulations of peripheral sensory neurons are selectively tuned to respond to cold, cool, warm, hot, and extremely hot temperatures. This functional segregation is mirrored by distinct patterns of thermosensitive TRP channel expression and distinct patterns of spinal cord projection among these neuronal subtypes (Patapoutian et al. 2003). Moreover, there is evidence that warm temperature transduction may occur in nonneuronal skin keratinocytes (Güler et al. 2002; Peier et al. 2002b; Xu et al. 2002; Chung et al. 2003, 2004) that then communicate this information to adjacent sensory neurons. Such segregation makes functional sense, in that the response patterns appropriate to intense heat or cold stimuli are different from those appropriate to a less extreme thermal challenge. In the former case, immediate withdrawal is of paramount importance, whereas in the latter, slower responses that reposition the entire animal and do not interfere with other ongoing physiological processes are more desirable.

The study by Rosenzweig et al. (2005) demonstrates definitively that dTRPA1 is essential for thermotaxis in larvae up to the third instar stage. However, thermotaxis behavior in adult flies is not addressed in this study. Moreover, as the authors acknowledge, they have not yet formally demonstrated that it is the thermosensory properties of dTRPA1, per se, that account for its importance to thermotaxis. A competing possibility is that dTRPA1 is required for the central processing of thermosensory information, a notion supported by this protein's expression in central neurons. In the case of Painless, acute withdrawal from noxious heat depends upon expression in peripheral multidendritic neurons (Tracey et al. 2003). One might, therefore, expect thermotaxis behavior to be driven by peripheral transduction mechanisms, as well. However, this need not be the case. The small body size of Drosophila larvae and the relatively slow kinetics of thermotaxis make it entirely possible that this process is driven by central, as opposed to peripheral thermotransduction mechanisms. Even in mammals, there appears to be a complex interplay between central and peripheral thermosensation, in that neurons in the preoptic/anterior hypothalamus both sense local temperature directly and integrate input from other central and peripheral thermosensory neurons (Boulant and Hardy 1974). Furthermore, while there is growing evidence that TRP channels contribute to peripheral thermosensation in mammals, and despite the expression of several TRP channels in the hypothalamus (Sasamura et al. 1998; Caterina et al. 1999; Liedtke and Friedman 2003), prevailing notions of central mammalian thermotransduction invoke TRP-independent mechanisms.

In C. elegans, while peripheral neurons have been shown to be essential for thermotaxis behavior (Mori and Ohshima 1995), there is no evidence, yet, of the participation of TRP channels in this response, although this organ- 
ism does express two TRPA homologs, in addition to five TRPVs, four TRPMs, and other TRPs. Thus, a monolithic model in which peripheral thermotransduction through TRP channels leads to centrally mediated behavioral responses is overly simplistic, as it fails to take into account the diverse needs of organisms to respond differentially as a function of temperature and anatomical location.

Rosenzweig et al. (2005) also indicate that orthologs of dTRPA1 are expressed in other arthropod species, including the mosquito, Anopheles gambiae. The potential importance of this observation is enormous, given that thermotaxis may contribute to the host-seeking behavior of this malaria-spreading vector (Enserink 2002). Should Anopheles TRPA1 play a role similar to that of dTRPA1, this protein might serve as an attractive target for the design of malaria prophylactic drugs.

If disruption of central dTRPA1-expressing neurons is sufficient to impair thermotaxis, what might be the physiological role(s) of this channel in other cell types? The dTRPA1 protein is also expressed in the corpus cardiacum, a neuroendocrine gland with some similarities to the mammalian pituitary gland (De Velasco et al. 2004). In butterflies this structure is important for temperature-dependent seasonal changes in wing pattern (Fukuda and Endo 1966), a striking observation given dTRPAl thermosensitivity. It is noteworthy that in $C$. elegans, the two cGMP-gated channels (TAX-2 and TAX4), which function in thermotaxis, are also required for chemosensation (Coburn and Bargmann 1996; Komatsu et al. 1996).

Further support for additional roles of dTRPA1 has come from the study of its orthologs in other species. Whereas warm temperature is the only known activator of dTRPA1 so far, mammalian TRPA1 is capable of responding to a number of physical and chemical stimuli. For example, this protein can be activated by pungent chemicals such as mustard oil (allyl isothiocyanate) and cinnamaldehyde (Story et al. 2003; Bandell et al. 2004; Jordt et al. 2004). There is also evidence to support a role for TRPA1 in auditory and vestibular mechanotransduction in zebrafish and mice (Corey et al. 2004). With regards to temperature gating, there is apparent disagreement about the thermotransduction capabilities of mammalian TRPA1. While some investigators have reported activation of this channel by extremely cold (as opposed to warm) temperatures $\left(\leq 17^{\circ} \mathrm{C}\right)$ (Story et al. 2003), other investigators have failed to reproduce this effect, and have argued that it represents an indirect response mediated by elevated intracellular $\mathrm{Ca}^{2+}$ (Jordt et al. 2004). In fact, activation of bradykinin receptors stimulates a TRPA1-like current in neurons in the dorsal root ganglia and activates TRPA1 in vitro (Bandell et al. 2004), possibly via a similar $\mathrm{Ca}^{2+}$ increase. As described above, Painless is essential for withdrawal from either noxious heat or noxious mechanical stimuli. In addition, there is evidence that mammalian TRPV1 and TRPV4 may participate in osmo/mechanosensation (Liedtke et al. 2000; Strotmann et al. 2000; Wissenbach et al. 2000; Birder et al. 2002; Liedtke and Friedman 2003; Suzuki et al. 2003) in addition to thermosensory processes (Ca- terina et al. 1997; Güler et al. 2002; Watanabe et al. 2002). Thus, a more extensive analysis of dTRPA1 function in Drosophila is warranted.

Indeed, one of the few limitations of the present study is the relatively low resolution of the thermotaxis readout. While this assay is clearly adequate to discern a phenotype in larvae deficient in TRPA1, the steepness of the gradient used and the assay's poor temporal resolution do not offer the opportunity for a thorough mechanistic analysis of thermotaxis and the contributions of dTRPA1 to this process. Still, some insights can be gleaned from these results. For example, assuming that dTRPA1 is acting as a primary transducer of warmth in this assay, the diminished occupancy of warm temperatures by larvae lacking this protein suggests that their thermal selection is at least partially driven by avoidance of unfavorable temperatures, as opposed to attraction towards favorable temperatures. The model that stimulation of dTRPAl leads to an avoidance response is supported by the observation that this channel is activated by warm temperatures with a threshold of $\sim 27^{\circ} \mathrm{C}$.

The analysis by Rosenzweig et al. (2005) raises many questions. What will happen in larvae that have been acclimated to a different temperature? Will their preferred thermal occupancy remain the same, as observed in adult Drosophila (Sayeed and Benzer 1996) or be shifted, as observed in C. elegans (Mori 1999)? If a shift does occur, would it be associated with a resetting of dTRPA1 sensitivity? What are the transducers that drive thermotactic avoidance of cold temperatures? Is there a hierarchy of thermosensory proteins that are most functionally relevant over discrete temperature ranges? What are the events downstream of dTRPAl that dictate thermotaxis? What is the nature of the relevant neuronal circuitry? Does thermotaxis in Drosophila involve the competing activities of neurons in opposite directions as has been proposed in C. elegans (Mori and Ohshima 1995)? The answers to these and related questions should emerge over the next few years through a thorough genetic and pharmacological analysis of thermotaxis in Drosophila.

\section{References}

Bandell, M., Story, G.M., Hwang, S.W., Viswanath, V., Eid, S.R., Petrus, M.J., Earley, T.J., and Patapoutian, A. 2004. Noxious cold ion channel TRPAl is activated by pungent compounds and bradykinin. Neuron 41: 849-857.

Birder, L.A., Nakamura, Y., Kiss, S., Nealen, M.L., Barrick, S., Kanai, A.J., Wang, E., Ruiz, G., De Groat, W.C., Apodaca, G., et al. 2002. Altered urinary bladder function in mice lacking the vanilloid receptor TRPV1. Nat. Neurosci. 5: 856-860.

Boulant, J.A. and Hardy, J.D. 1974. The effect of spinal and skin temperatures on the firing rate and thermosensitivity of preoptic neurones. J. Physiol. 240: 639-660.

Caterina, M.J., Schumacher, M.A., Tominaga, M., Rosen, T.A., Levine, J.D., and Julius, D. 1997. The capsaicin receptor: A heat-activated ion channel in the pain pathway. Nature 389: 816-824.

Caterina, M.J., Rosen, T.A., Tominaga, M., Brake, A.J., and Julius, D. 1999. A capsaicin-receptor homologue with a high threshold for noxious heat. Nature 398: 436-441. 
Caterina, M.J., Leffler, A., Malmberg, A.B., Martin, W.J., Trafton, J., Petersen-Zeitz, K.R., Koltzenburg, M., Basbaum, A.I., and Julius, D. 2000. Impaired nociception and pain sensation in mice lacking the capsaicin receptor. Science 288: 306-313.

Cho, S.W., Choi, K.Y., and Park, C.S. 2004. A new putative cyclic nucleotide-gated channel gene, cng-3, is critical for thermotolerance in Caenorhabditis elegans. Biochem. Biophys. Res. Commun. 325: 525-531.

Chung, M.K., Lee, H., and Caterina, M.J. 2003. Warm temperatures activate TRPV4 in mouse 308 keratinocytes. J. Biol. Chem. 278: 32037-32046.

Chung, M.K., Lee, H., Mizuno, A., Suzuki, M., and Caterina, M.J. 2004. TRPV3 and TRPV4 mediate warmth-evoked currents in primary mouse keratinocytes. J. Biol. Chem. 279: 21569-21575.

Coburn, C.M. and Bargmann, C.I. 1996. A putative cyclic nucleotide-gated channel is required for sensory development and function in C. elegans. Neuron 17: 695-706.

Corey, D.P., Garcia-Añoveros, J., Holt, J.R., Kwan, K.Y., Lin, S.Y., Vollrath, M.A., Amalfitano, A., Cheung, E.L., Derfler, B.H., Duggan, A., et al. 2004. TRPAl is a candidate for the mechanosensitive transduction channel of vertebrate hair cells. Nature 432: 723-770.

Davis, J.B., Gray, J., Gunthorpe, M.J., Hatcher, J.P., Davey, P.T., Overend, P., Harries, M.H., Latcham, J., Clapham, C., Atkinson, K., et al. 2000. Vanilloid receptor-1 is essential for inflammatory thermal hyperalgesia. Nature 405: 183-187.

De Velasco, B., Shen, J., Go, S., and Hartenstein, V. 2004. Embryonic development of the Drosophila corpus cardiacum, a neuroendocrine gland with similarity to the vertebrate pituitary, is controlled by sine oculis and glass. Dev. Biol. 274: $280-294$.

Enserink, M. 2002. What mosquitoes want: Secrets of host attraction. Science 298: 90-92.

Fukuda, S. and Endo, K. 1966. Hormonal control of the development of seasonal forms of the butterfly Polygonia caureum. Proc. Japan. Acad. 42: 1082-1087.

Güler, A.D., Lee, H., Iida, T., Shimizu, I., Tominaga, M., and Caterina, M. 2002. Heat-evoked activation of the ion channel, TRPV4. J. Neurosci. 22: 6408-6414.

Jordt, S.E., Bautista, D.M., Chuang, H.H., McKemy, D.D., Zygmunt, P.M., Hogestätt, E.D., Meng, I.D., and Julius, D. 2004. Mustard oils and cannabinoids excite sensory nerve fibres through the TRP channel ANKTM1. Nature 427:260265.

Komatsu, H., Mori, I., Rhee, J.S., Akaike, N., and Ohshima, Y. 1996. Mutations in a cyclic nucleotide-gated channel lead to abnormal thermosensation and chemosensation in C. elegans. Neuron 17: 707-718.

Liedtke, W. and Friedman, J.M. 2003. Abnormal osmotic regulation in trpv $4^{-/-}$mice. Proc. Natl. Acad. Sci. 100: 13698-13703.

Liedtke, W., Choe, Y., Marti-Renom, M.A., Bell, A.M., Denis, C.S., Sali, A., Hudspeth, A.J., Friedman, J.M., and Heller, S. 2000. Vanilloid receptor-related osmotically activated channel (VR-OAC), a candidate vertebrate osmoreceptor. Cell 103: $525-535$.

Liu, L., Yermolaieva, O., Johnson, W.A., Abboud, F.M., and Welsh, M.J. 2003. Identification and function of thermosensory neurons in Drosophila larvae. Nat. Neurosci. 6: 267-273.

McKemy, D.D., Nenhausser, W.M., and Julius, D. 2002. Identification of a cold receptor reveals a general role for TRP channels in thermosensation. Nature 416: 52-58.

Montell, C., Birnbaumer, L., and Flockerzi, V. 2002. The TRP channels, a remarkably functional family. Cell 108: 595-598.

Mori, I. 1999. Genetics of chemotaxis and thermotaxis in the nematode Caenorhabditis elegans. Annu. Rev. Genet. 33: 399422 .
Mori, I. and Ohshima, Y. 1995. Neural regulation of thermotaxis in Caenorhabditis elegans. Nature 376: 344-348.

Nishiyama, S., Nara, T., Homma, M., Imae, Y., and Kawagishi, I. 1997. Thermosensing properties of mutant aspartate chemoreceptors with methyl-accepting sites replaced singly or multiply by alanine. J. Bacteriol. 179: 6573-6580.

Patapoutian, A., Peier, A.M., Story, G.M., and Viswanath, V. 2003. ThermoTRP channels and beyond: Mechanisms of temperature sensation. Nat. Rev. Neurosci. 4: 529-539.

Peier, A., Moqrich, A., Hergarden, A., Reeve, A., Andersson, D., Story, G., Earley, T., Dragoni, I., McIntyre, P., Bevan, S., et al. 2002a. A TRP channel that senses cold stimuli and menthol. Cell 108: 705-715.

Peier, A.M., Reeve, A.J., Andersson, D.A., Moqrich, A., Earley, T.J., Hergarden, A.C., Story, G.M., Colley, S., Hogenesch, J.B., McIntyre, P., et al. 2002b. A heat-sensitive TRP channel expressed in keratinocytes. Science 296: 2046-2049.

Rosenzweig, M., Brennan, K.M., Tayler, T.D., Phelps, P.O., Patapoutian, A., and Garrity, P.A. 2005. The Drosophila ortholog of vertebrate TRPA1 regulates thermotaxis. Genes \& Dev. (this issue).

Sasamura, T., Sasaki, M., Tohda, C., and Kuraishi, Y. 1998. Existence of capsaicin-sensitive glutamatergic terminals in rat hypothalamus. Neuroreport 9: 2045-2048.

Sayeed, O. and Benzer, S. 1996. Behavioral genetics of thermosensation and hygrosensation in Drosophila. Proc. Natl. Acad. Sci. 93: 6079-6084.

Smith, G.D., Gunthorpe, M.J., Kelsell, R.E., Hayes, P.D., Reilly, P., Facer, P., Wright, J.E., Jerman, J.C., Walhin, J.P., Ooi, L., et al. 2002. TRPV3 is a temperature-sensitive vanilloid receptor-like protein. Nature 418: 186-190.

Story, G.M., Peier, A.M., Reeve, A.J., Eid, S.R., Mosbacher, J., Hricik, T.R., Earley, T.J., Hergarden, A.C., Andersson, D.A., Hwang, S.W., et al. 2003. ANKTM1, a TRP-like channel expressed in nociceptive neurons, is activated by cold temperatures. Cell 112: 819-829.

Strotmann, R., Harteneck, C., Nunnenmacher, K., Schultz, G., and Plant, T.D. 2000. OTRPC4, a nonselective cation channel that confers sensitivity to extracellular osmolarity. Nat. Cell Biol. 2: 695-702.

Suzuki, M., Mizuno, A., Kodaira, K., and Imai, M. 2003. Impaired pressure sensation in mice lacking TRPV4. I. Biol. Chem. 278: 22664-22668.

Tracey, W.D., Wilson, R.I., Laurent, G., and Benzer, S. 2003. painless, a Drosophila gene essential for nociception. Cell 113: 261-273.

Viswanath, V., Story, G.M., Peier, A.M., Petrus, M.J., Lee, V.M., Hwang, S.W., Patapoutian, A., and Jegla, T. 2003. Opposite thermosensor in fruitfly and mouse. Nature 423: 822-823.

Watanabe, H., Vriens, J., Suh, S.H., Benham, C.D., Droogmans, G., and Nilius, B. 2002. Heat-evoked activation of TRPV4 channels in a HEK293 cell expression system and in native mouse aorta endothelial cells. J. Biol. Chem. 277: 47044-47051.

Wissenbach, U., Bödding, M., Freichel, M., and Flockerzi, V. 2000. Trp12, a novel Trp related protein from kidney. FEBS Lett. 485: 127-134.

Xu, H., Ramsey, I.S., Kotecha, S.A., Moran, M.M., Chong, J.A., Lawson, D., Ge, P., Lilly, J., Silos-Santiago, I., Xie, Y., et al. 2002. TRPV3 is a calcium-permeable temperature-sensitive cation channel. Nature 418: 181-186.

Zars, T. 2001. Two thermosensors in Drosophila have different behavioral functions. J. Comp. Physiol. A 187: 235-242. 


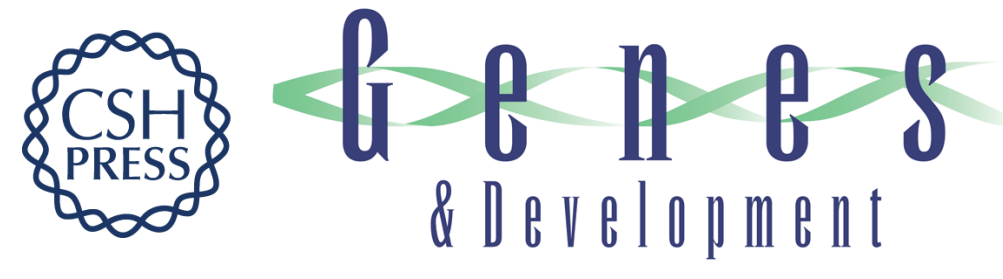

\section{Take a TRP to beat the heat}

Michael J. Caterina and Craig Montell

Genes Dev. 2005, 19:

Access the most recent version at doi:10.1101/gad.1294905

References This article cites 41 articles, 11 of which can be accessed free at: http://genesdev.cshlp.org/content/19/4/415.full.html\#ref-list-1

License

Email Alerting Receive free email alerts when new articles cite this article - sign up in the box at the top Service right corner of the article or click here.

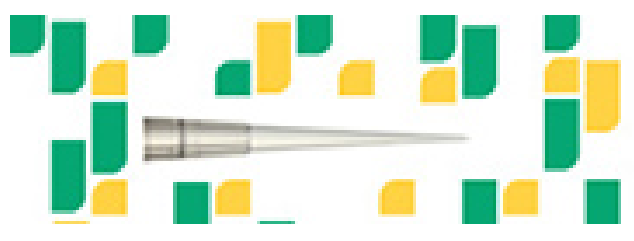

Focused on your science. 